\title{
The Ultrastructure of the Capsules of Diplococcus pneumoniae and Klebsiella pneumoniae Stained with Ruthenium Red
}

\author{
By E. LOUISE SPRINGER AND I. L. ROTH \\ Department of Microbiology, The University of Georgia, Athens, Georgia, 3060 I, U.S.A.
}

(Received 26 May 1972; revised 7 August 1972)

\section{SUMMAR Y}

Capsules of Diplococcus pneumoniae type III and Klebsiella pneumoniae type I were examined in the electron microscope using ruthenium red in combination with osmium tetroxide. The ability of this combination stain and fixative to stain polysaccharides has been well established. A slightly acid $\mathrm{pH}$ was necessary to obtain satisfactory capsular polysaccharide staining.

The capsules of both Diplococcus pneumoniae and Klebsiella pneumoniae were stained by the ruthenium red before alcohol dehydration and embedding in Epon 8I2. The capsule of $D$. pneumoniae had the appearance of a tightly woven mat. The capsule of $K$. pneumoniae had a fibrous appearance. Ruthenium red was found inside the plasma membrane of $D$. pneumoniae, but remained outside the cell membrane of $K$. pneumoniae.

\section{INTRODUCTION}

Early efforts to examine bacterial capsules by electron microscopy made use of whole organisms that were either stained with metal salts or were metal shadowed. Mudd, Heinmets \& Anderson (1943) published electron micrographs of whole Diplococcus pneumoniae stained with lead acetate or copper sulphate; only a hazy indistinct outline of the capsule was visible. After palladium shadowing, Labaw \& Mosley (1954) observed spindle shapes in the capsules of the Lisbonne strain of Escherichia coli. Studies of the cellulose capsule of whole cells of Acetobacter xylinum using palladium or palladium-gold shadowing revealed microfibrils comprising the capsule (Colvin \& Beer, I960; Millman \& Colvin, I96r).

Part of the problem in preserving and staining the bacterial capsule has been the lack of a suitable fixative and stain specific for acid mucopolysaccharides. In 1964, Luft used ruthenium red to stain acid mucopolysaccharides in animal tissues examined by electron microscopy. Pate \& Ordal (1967) used ruthenium red to demonstrate peripheral fibrils in Chondrococcus columnaris. Jones, Roth \& Sanders (I969) modified the procedure of Pate \& Ordal (I967) to visualize polysaccharide fibres in aquatic slime layers.

Ruthenium red might be useful in studying the ultrastructure of bacterial capsules. The purpose of this work was to examine, by electron microscopy, the ultrastructure of the capsules of Diplococcus pneumoniae type III and Klebsiella pneuomoniae type I using ruthenium red in combination with osmium tetroxide and several methods of dehydration and embedding. 


\section{Culture}

\section{METHODS}

Diplococcus pneumoniae type III (ATCC6303) and Klebsiella pneumoniae type I obtained from the Center for Disease Control, Atlanta, Georgia, were inoculated into starter cultures of brain heart infusion broth (Difco) supplemented with $2 \%(\mathrm{w} / \mathrm{v})$ sucrose. After $16 \mathrm{~h}$ of incubation at $37^{\circ} \mathrm{C}$, fresh media was inoculated and allowed to incubate under static conditions. The turbidity of the culture and the production of acid were followed using a Bausch and Lomb Spectronic 20 spectrophotometer at $660 \mathrm{~nm}$ and a Corning model $\mathrm{I} 0 \mathrm{pH}$ meter. The bacteria were harvested by centrifugation when late log phase was reached and the maximum amount of capsule was present.

\section{Staining and fixation}

The pellet was suspended in $\mathrm{I} \mathrm{ml}$ of ruthenium red ( $\mathrm{K} \& \mathrm{~K}$ Laboratories, Plainview, New York, U.S.A.) ( $1.5 \mathrm{mg} / \mathrm{ml}$ ) in water, I ml 3.6\% (w/v) glutaraldehyde (Ladd Research Industries Burlington, Vermont, U.S.A.) and I $\mathrm{ml}$ of $0.2 \mathrm{M}$-cacodylate buffer (Ladd Research Industries), $\mathrm{pH} 6 \cdot 5$, and held for $\mathrm{I} h$ at $\mathrm{o}^{\circ} \mathrm{C}$.

Stainless controls were incubated with an additional $\mathrm{ml}$ of buffer in place of ruthenium red. Next, the bacteria were washed with three changes of buffer, and suspended in a mixture containing I $\mathrm{ml}$ of ruthenium red $(\mathrm{I} \cdot 5 \mathrm{mg} / \mathrm{ml})$, I $\mathrm{ml} 4 \%(\mathrm{w} / \mathrm{v})$ osmium tetroxide and I $\mathrm{ml}$ of buffer and incubated for $3 \mathrm{~h}$ at $27^{\circ} \mathrm{C}$. Following this second fixation, they were rinsed once with buffer, dehydrated and embedded by one of three methods.

\section{Dehydration and embedment}

Luft's method. The bacteria were dehydrated in successive Io min steps of $30 \%(\mathrm{v} / \mathrm{v})$, $50 \%(\mathrm{v} / \mathrm{v}), 70 \%(\mathrm{v} / \mathrm{v}), 90 \%(\mathrm{v} / \mathrm{v})$ ethanol and two washings with absolute ethanol for $15 \mathrm{~min}$ each. They were next suspended in a mixture of three parts ethanol to one part of an Epon $8 \mathrm{I} 2$ mixture. The Epon $8 \mathrm{I} 2$ mixture contained $3 \mathrm{ml}$ of mixture A (62 $\mathrm{ml}$ of Epon $8 \mathrm{I} 2$ and roo $\mathrm{ml}$ of dodecenyl succinic anhydride; Ladd Research Industries) and $7 \mathrm{ml}$ of mixture B ( $100 \mathrm{ml}$ Epon 812 and $89 \mathrm{ml}$ of methylnadic anhydride; Ladd Research Industries) and was incubated $30 \mathrm{~min}$ at room temperature. The bacteria were transferred to a solution that was I part alcohol and I part Epon mixture and held for $30 \mathrm{~min}$ at room temperature. They were then harvested by centrifugation and transferred to a BEEM capsule (Polysciences, Warrington, Pennsylvania, U.S.A.) and a fresh Epon mixture containing the amine accelerator, tridi-methylamino-methyl phenol (Ladd Research Industries; $0 \cdot 15 \%$, v/v), was added. The embedding was then cured for $24 \mathrm{~h}$ at $60^{\circ} \mathrm{C}$ (Luft, I96I).

Craig's method. In the Craig, Frajola \& Greider's (I962) procedure using Epon 8I2 dehydration and embedding in Epon 8I2, the bacteria were dehydrated in ascending concentrations of Epon 8I 2 in $0.2 \mathrm{M}$-cacodylate buffer, $\mathrm{pH} 6.5$, following this schedule: $25 \%$ $(\mathrm{v} / \mathrm{v})$ buffer and $75 \%(\mathrm{v} / \mathrm{v})$ Epon $8 \mathrm{I} 2$ for I h, transferred to a mixture of $55 \%(\mathrm{v} / \mathrm{v})$ Epon $8 \mathrm{I} 2$ and $45 \%(\mathrm{v} / \mathrm{v})$ hexahydrophthallic anhydride (HHPA) (Polysciences) for $2 \mathrm{~h}$ at room temperature. Next the bacteria were placed in a fresh solution of $55 \%(\mathrm{v} / \mathrm{v})$ Epon $8 \mathrm{I} 2$ and $45 \%$ (v/v) HHPA now including $2 \%$ (v/v) benzyldimethylamine (BDMA; Ladd Research Industries) for $2 \mathrm{~h}$. After $2 \mathrm{~h}$ the bacteria were placed in a fresh solution of Epon 8 12 , HHPA and BDMA (in the same concentrations as before) and cured $\mathrm{I} 2 \mathrm{~h}$ at $55^{\circ} \mathrm{C}$.

Staubli's method. In Staubli's (1963) method for dehydration and embedding, the watersoluble resin Durcupan is used to dehydrate the bacteria and the water insoluble Araldite 502 is used for embedding. The bacteria were dehydrated at $0^{\circ} \mathrm{C}$ with Durcupan (Fluka AG, Buchs SG, Switzerland) in successive I5 min steps of $50 \%(\mathrm{v} / \mathrm{v}), 70 \%(\mathrm{v} / \mathrm{v})$ and 
$90 \%(\mathrm{v} / \mathrm{v})$ Durcupan in water with two washings of $45 \mathrm{~min}$ each in $100 \%$ Durcupan. The bacteria impregnated with Durcupan were embedded in Araldite 502 (Ciba Products, Fairlawn, New Jersey, U.S.A.) at $50^{\circ} \mathrm{C}$ as follows: $70 \%$ (v/v) Durcupan at $30 \%(\mathrm{v} / \mathrm{v})$ Araldite I (one part Araldite 502 and one part dodecenyl succinic anhydride) for I h; $50 \%(\mathrm{v} / \mathrm{v})$ Durcupan and $50 \%(\mathrm{v} / \mathrm{v})$ Araldite I for I h; three washes of 30 min each with Araldite II (Araldite I $+2 \%$, v/v, 2,4,6-tris-dimethylaminomethyl phenol; Ladd Research Industries) and placement in a BEEM capsule with fresh Araldite II to polymerize at $50{ }^{\circ} \mathrm{C}$ for $24 \mathrm{~h}$.

Sections were cut with an LKB Ultratome Type 480 A with glass knives made on a LKB Knifemaker Type 780r A. The sections were lifted from distilled water on copper grids. Contrast of some sections was enhanced by treatment with saturated aqueous uranyl acetate for 15 min as suggested by Watson (1958). All of the sections were examined with a JEM (Japan Electron Optics Laboratory, Tokyo, Japan) Model 6-C electron microscope.

\section{RESULTS}

\section{Diplococcus pneumoniae stained with ruthenium red}

Bacteria dehydrated with alcohol and embedded in Epon 8I2 showed dense fibrous capsules characterized by a woven or mat-like structure. Additional staining also occurred in and beyond the plasma membrane (Fig. I). In Fig. 2, some of the capsule has sloughed off showing the fibrous structure of the capsule more clearly; again intense staining of the plasma membrane and part of the cytoplasm has occurred. A well preserved mesosome is also present. Since the contrast in neither organism has been enhanced by additional staining, the increased density of the capsule and the plasma membrane can be attributed to the ruthenium red-osmium coupled reaction. Bacteria dehydrated either in Epon 812 and embedded in Epon 812 or dehydrated in Durcupan and embedded in Araldite 502 did not appear to retain capsule and resembled the stainless control which was dehydrated with alcohol and embedded in Epon 8r2 (Fig. 3).

\section{Klebsiella pneumoniae stained with ruthenium red}

Bacteria dehydrated with alcohol and embedded in Epon 8I 2 display well preserved and stained capsule with no increased ruthenium red staining of the plasma membrane and cytoplasm like that seen in pneumococcus treated identically. A variety of capsule forms are visible within the same micrograph. This probably indicates multiple effects of dehydration on the capsular gel (Fig. 4). The spike-like structure of the bacterial capsule is clearly evident in Fig. 4. Other bacteria in the same micrograph have overlapping spikes creating a net-like appearance which is most evident in the central bacterium in Fig. 5. Some of the fibrils of capsule seem to have cross-linking structures between them as in Fig. 6 . To the left of the organism cut longitudinally, a transverse section through the capsule showing the fibril tips is seen.

Dehydrating and embedment with Epon 8I 2 caused separation of the spiked capsular fibrils into thin strands (Fig. 7). In bacteria dehydrated with Durcupan and embedded in Araldite 502, better preservation of capsular fibrils was noted than was evident after alcohol dehydration and embedment in Epon 8I2. The fibrils are nearly uniform in length and width (Fig. 8). A section through the capsule portion of the organism shows the individual fibrils, as well as some of the wall. Bacteria fixed in the absence of ruthenium red and dehydrated and embedded by all the three described methods showed faint fibrils exterior to the wall (Fig. 9). However, since contrast was poor without ruthenium red, aqueous uranyl acetate was used to enhance contrast. 

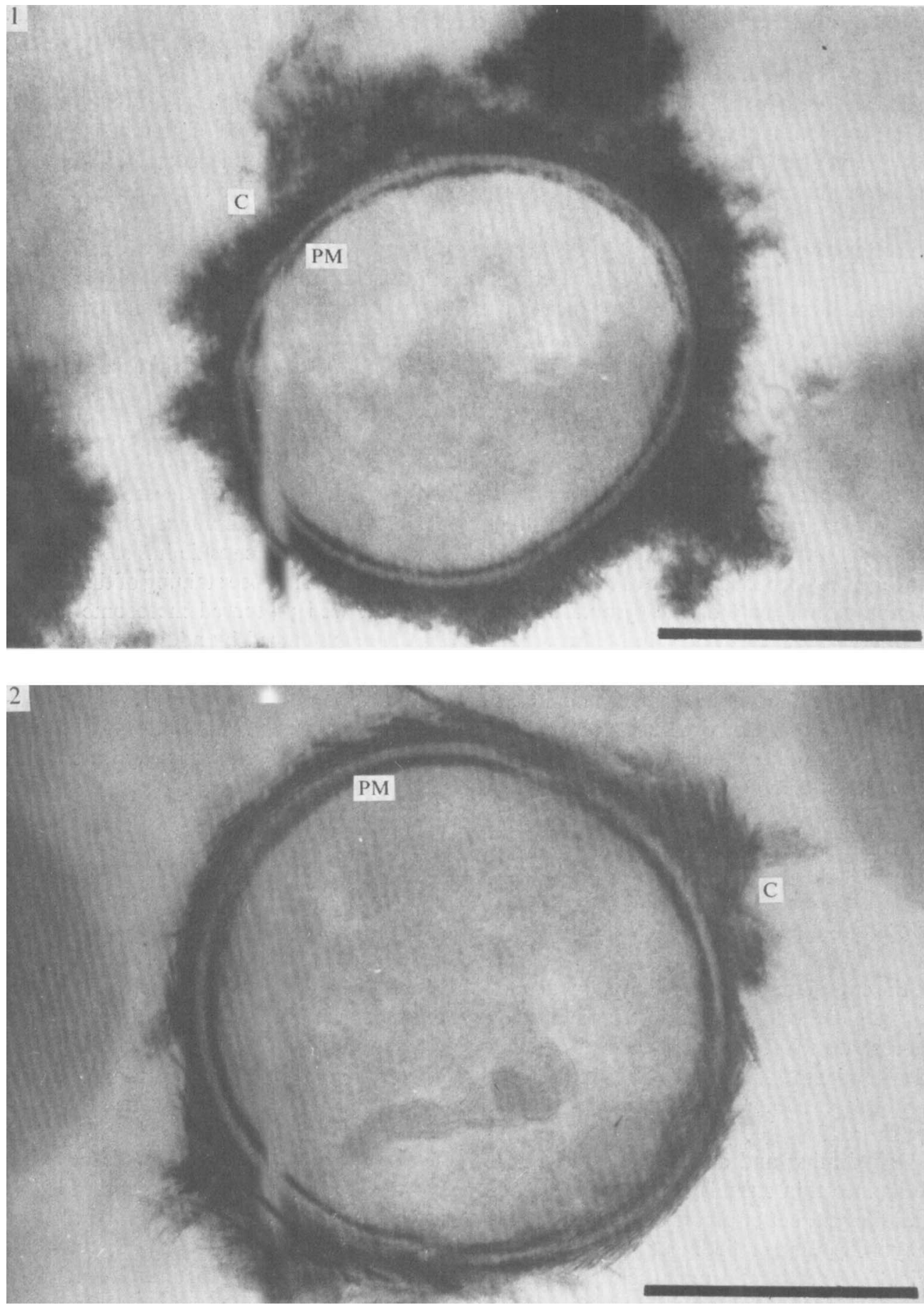

Fig. I, 2. Diplococcus pneumoniae stained with ruthenium red, dehydrated with alcohol and embedded in Epon 812. The mat-like capsule (C) surrounds each bacterium. Ruthenium red penetration is evident at the plasma membrane (PM) and into the cytoplasm. The marker represents $0.5 \mu \mathrm{m}$. 

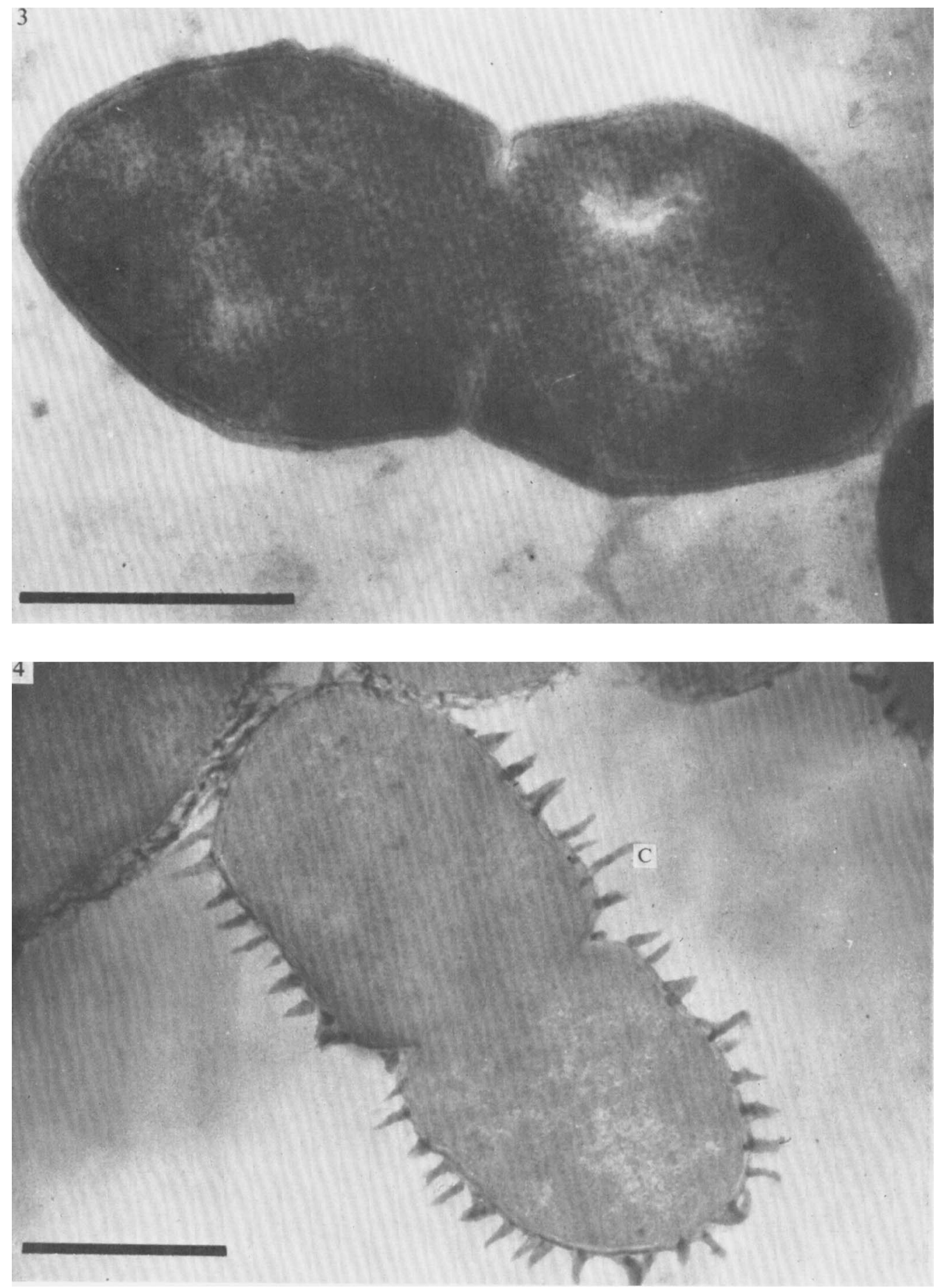

Fig. 3. Diplococcus pneumoniae, stainless control dehydrated and embedded as cells in Fig. I and 2. No capsular material is evident external to the wall nor is the plasma membrane heavily stained as in Fig. I and 2. The marker represents $0.5 \mu \mathrm{m}$.

'Fig. 4. Klebsiella pneumoniae stained with ruthenium red, dehydrated with alcohol and embedded in Epon 812. Capsular fibrils (C) are seen at regular intervals along the wall. The marker represents $0.5 \mu \mathrm{m}$. 

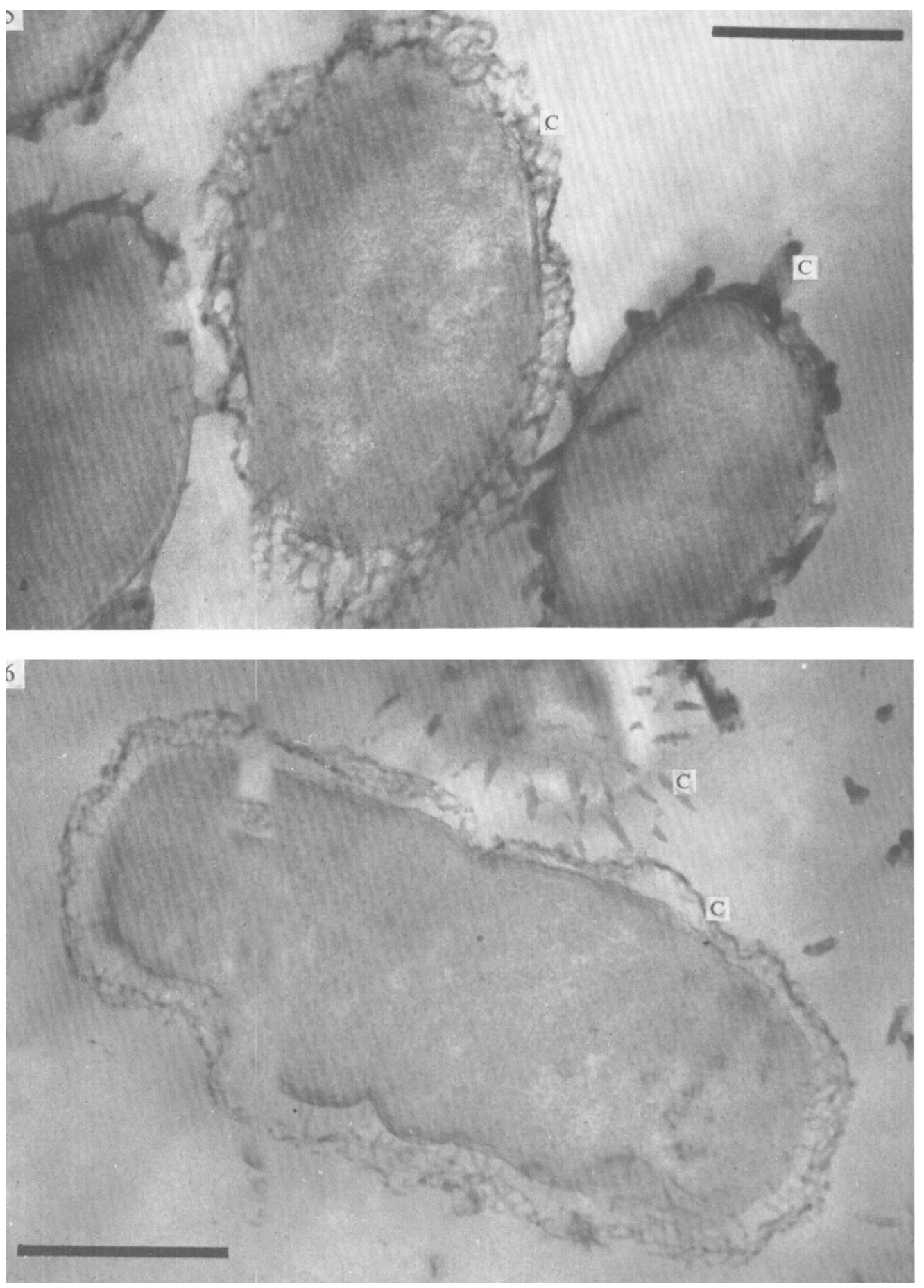

Fig. 5, 6. Klebsiella pneumoniae treated as Fig. 4. Fig. 5: The central bacterium has overlapping capsular fibrils (C) creating a net-like appearance. Fig. 6: Capsular fibrils (C) seem to have crosslinking structures between them. The spike-like nature of the dehydrated capsule (C) is seen in the tangentially cut bacterium. The markers represent $0.5 \mu \mathrm{m}$. 

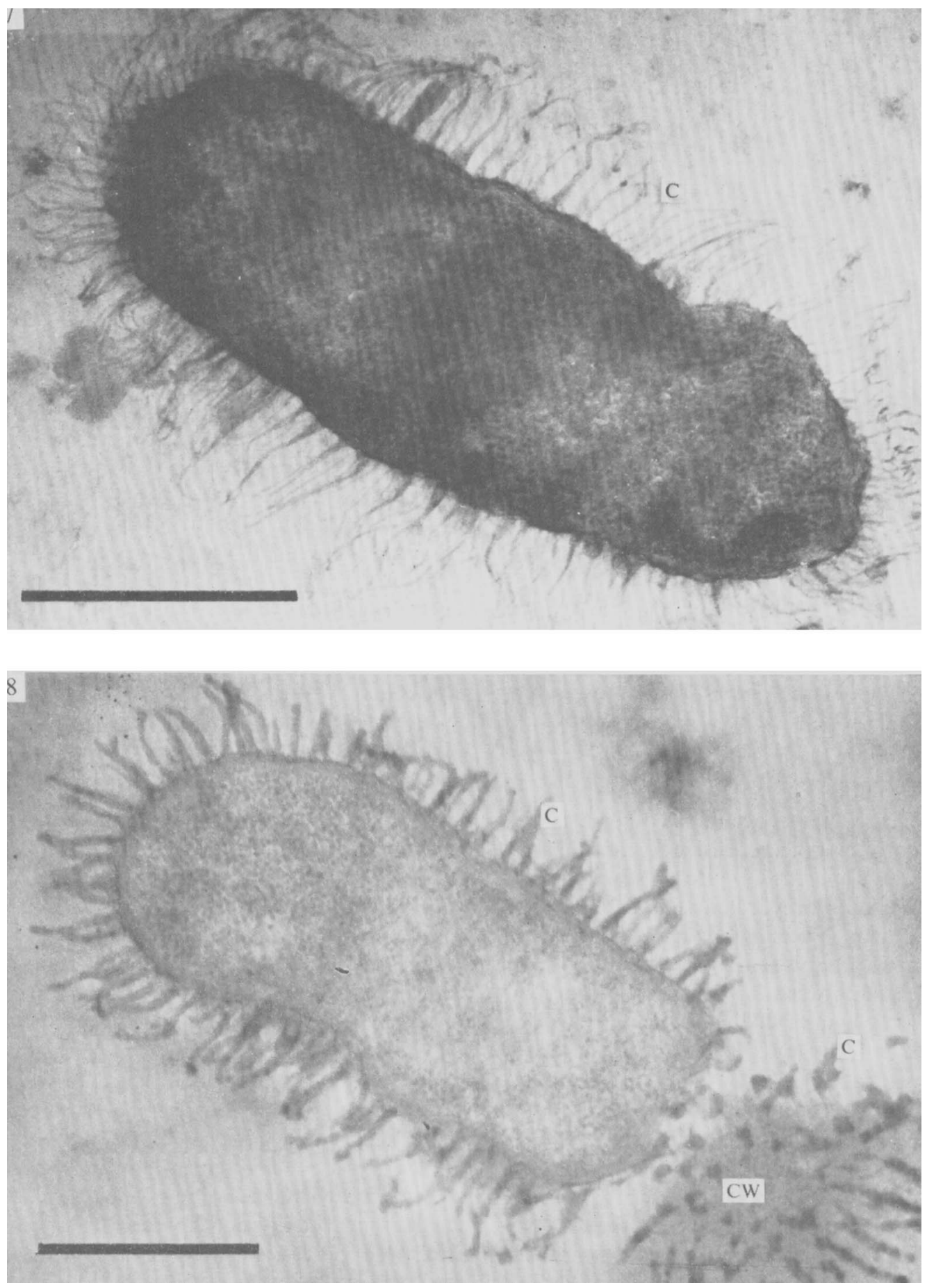

Fig. 7. Klebsiella pneumoniae stained with ruthenium red, dehydrated with Epon 8I 2 and embedded with Epon 8 I 2. The capsule (C) is composed of slender, thread-like fibrils. The marker represents $0.5 \mu \mathrm{m}$.

Fig. 8. Klebsiella pneumoniae stained with ruthenium red, dehydrated with Durcupan and embedded in Araldite 502. Capsular fibrils (C) are seen at regular intervals along the wall. A bacterium tangentially cut through the capsule (C) also reveals the wall (CW). The marker represents $0.5 \mu \mathrm{m}$. 


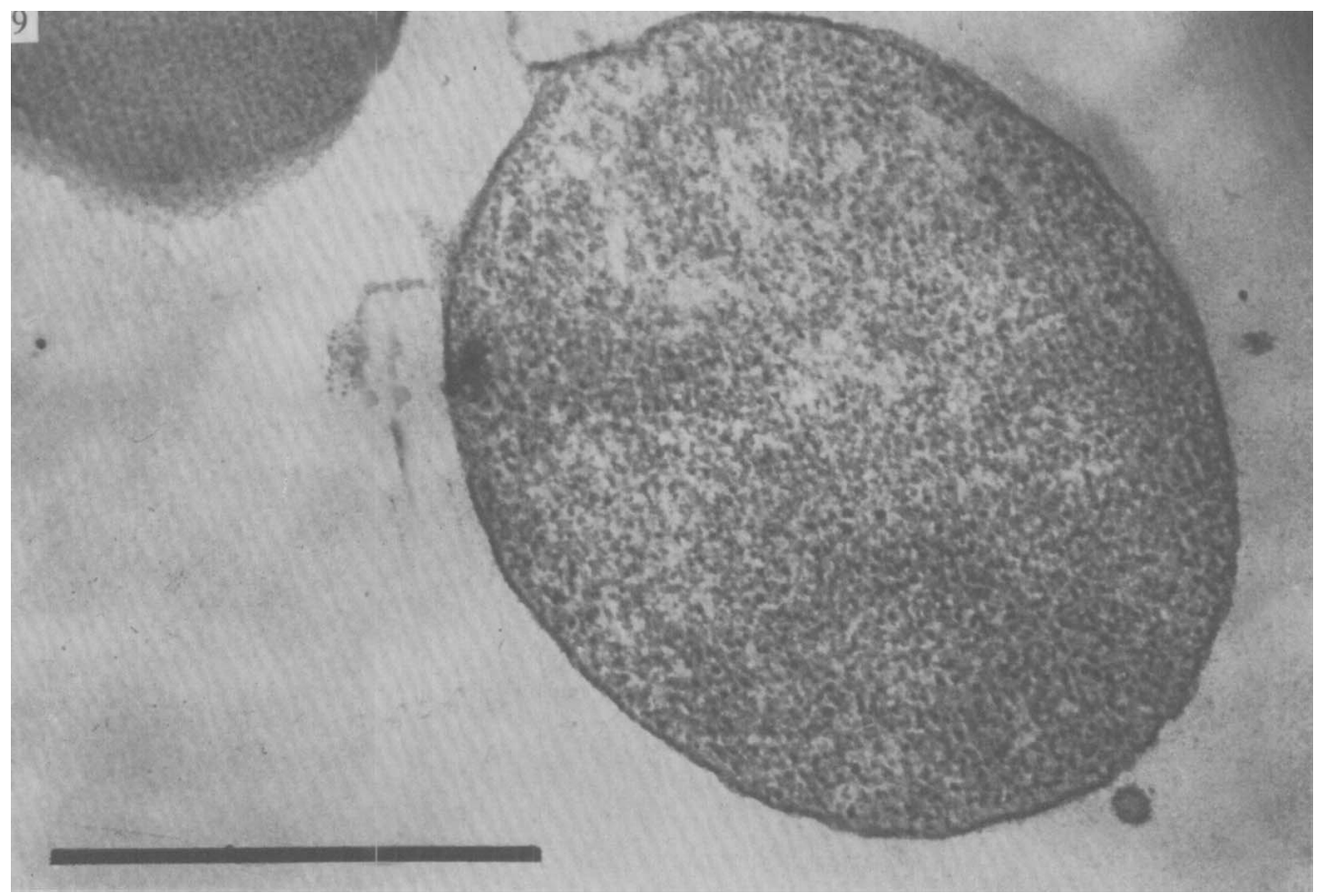

Fig. 9. Klebsiella pneumoniae stainless control representative of all three dehydration and embedment procedures. Some faintly electron-dense capsular fibrils were preserved by this fixation procedure at $\mathrm{pH} 6.5$. The marker represents $0.5 \mu \mathrm{m}$.

Comparison of Klebsiella capsule preservation after either alcohol, Epon 812 or Durcupan dehydration

The appearance of the capsule after any of the three dehydration procedures was fairly consistent (i.e. repetitive fibrils external to the wall). However, differences in fibril length and width and tendency to overlap varied considerably with the dehydrating procedure used. Capsules dehydrated with alcohol (Fig. 4) or Durcupan (Fig. 8) had fibrils which averaged I $56 \mathrm{~nm}$ by $32 \mathrm{~nm}$; whereas capsules dehydrated in Epon 8I 2 (Fig. 7) had long (235 to $236 \mathrm{~nm}$ ) and thin $(7$ to $8 \mathrm{~nm}$ ) fibrils. The fibrils resulting from Epon 8I 2 dehydration of capsules were $60 \%$ longer and only $23 \%$ was wide as those dehydrated with alcohol or Durcupan (Table I). These ranges were established by making ten measurements on specimens dehydrated by each procedure.

\section{DISCUSSION}

Although the technique of Mudd et al. (1943) for preserving and increasing the electrondensity of the capsule of Diplococcus pneumoniae permitted visualization of the capsule in the electron microscope for the first time, fine structural detail was not visualized and the metal salts used precipitated the capsule polysaccharide and destroyed the gel matrix. Metal shadowing used by Ohad, Danon \& Hestrin (1962) showed that the capsule of Acetobacter xylinum was composed of many fibrils which extended outwards from the bacterial surface. Neither of these reports included studies of ultrathin sections. 
Table I. Range of dimensions of capsule fibrils of Klebsiella pneumoniae

\begin{tabular}{llc} 
& \multicolumn{2}{c}{ Fibril } \\
\cline { 2 - 3 } length & width \\
Alcohol & I46 to $160 \mathrm{~nm}$ & 37 to $40 \mathrm{~nm}$ \\
Durcupan & I53 to $166 \mathrm{~nm}$ & 24 to $27 \mathrm{~nm}$ \\
Epon 812 & 253 to $267 \mathrm{~nm}$ & 7 to $8 \mathrm{~nm}$
\end{tabular}

In Diplococcus pneumoniae and Klebsiella pneumoniae fixed and stained with ruthenium red-osmium tetroxide in $0.2 \mathrm{M}$-cacodylate buffer at $\mathrm{pH} \mathrm{7.3}$ as used by Pate \& Ordal (1967), no staining of the capsule occurred. The $\mathrm{pH}$ of the buffer was lowered to 6.5 as for uptake of ruthenium red by polygalacturonic acid (Stoddart \& Tipton, 1968). This $\mathrm{pH}$ also falls within the recommended limits (pH 6.5 to 8.0) for optimal fixation of biological specimens (Millonig \& Marinozzi, 1968), and is satisfactory for retention of the capsule on the bacterial surface, as Bernheimer (I953) reported that below pH 6.5 the capsule of D. pneumoniae is lost. The electron-density of the capsule of both organisms was increased after fixation and staining at $\mathrm{pH} 6.5$, making visualization of the capsule fibres possible. The action of ruthenium red, as suggested by Luft (197I), involves the formation of an electron dense deposit with $\mathrm{OsO}_{4}$ at the location of polysaccharides. The ability of ruthenium red to stain polysaccharides has been well established in studies with both mammalian and plant cells. Since the capsules of Diplococcus and Klebsiella are polysaccharides, the electron-dense fibrils external to the wall of both organisms, which were stained with ruthenium redosmium tetroxide, are considered to be capsular fibrils.

When water is removed from specimens by displacement with Durcupan or Epon 812 (Craig et al. 1962) instead of alcohol dehydration, the chemical effects of dehydration are quite different. The epoxides react with amino, imidazole, and carboxyl groups of proteins, as well as sulphhydryl groups of denatured proteins (Millonig \& Marinozzi, I968) but not with carbohydrates. If epoxides react with the carbohydrate components of the cells, the reaction would be unlike that with alcohol. Indeed, the epoxy resins may maintain the dielectric constant between adjacent polysaccharide polymers (Fig. 7,8) and thereby prevent the overlapping of capsule fibrils seen in alcohol dehydration (Fig. 4, 5, 6). The preservation of the bacteria following Durcupan dehydration was as good as with alcohol dehydration; however, the capsule fibrils of Klebsiella revealed less overlapping (Fig. 8). The tendency of the fibrils to overlap seemed to be completely overcome with Epon 8I2 dehydration. Since both Epon 8I2 and Durcupan are epoxides, the difference in preservation of the capsular fibrils may reside in the degree to which the dielectric constants between the fibril polymers were lowered, permitting attraction between polymers and eventual annealing. According to Wilkinson, Duguid \& Edmunds (1954), the capsule of Klebsiella aerogenes contains almost $95 \%$ water. Klebsiella pneumoniae has a capsule with a fibrous structure capable of binding large amounts of water. The preservation of many long, thin fibrils of capsular material more probably represents the natural hydrated state of the capsule than capsule fibrils which are short, thick and offer little surface for the binding of water. Thus, these micrographs of $K$. pneumoniae offer ultrastructural evidence in support of the finding of Wilkinson et al. (1954).

The slender fibrillar structures in Fig. 7 and 8 are also in keeping with the proposal of Heidelberger, Kendall \& Scherp (1936) that capsular carbohydrate is in thread-shaped polymers. Hershey (1940) postulated that the surface of capsulated bacteria is covered with projecting molecules or fibrils after his experiments with the absorption of antibody to the 
capsule surface revealed that a greater uptake of antibody occurred than was necessary to form a single surface layer of closely packed molecules. Electron micrographs of metalshadowed Acetobacter xylinum (Colvin \& Beer, 1960) and Escherichia coli Lisbonne strain (Labaw \& Mosley, I954) also, show the respective capsules to be composed of many fibrils.

In the micrographs of Diplococcus pneumoniae (Fig. I and 2) stained with ruthenium red, dehydrated with alcohol and embedded in Epon 8r 2, there is intense staining of the plasma membrane and cytoplasm adjacent to it; while Klebsiella pneumoniae treated identically shows no such staining of the plasma membrane. In the only other study of the effect of ruthenium red on a pure culture of bacteria, Pate \& Ordal (1967) found no increased staining of the plasma membrane of the myxobacterium Chondrococcus columaris. Since Chondrococcus is considered to have a Gram-negative type wall (Lautrop, Reyn \& Birch-Anderson, 1964); Klebsiella would be expected to respond to ruthenium red in a similar manner, i.e. the ruthenium red would remain outside the wall. The fact that the ruthenium red penetrated the plasma membrane of $D$. pneumoniae indicates a greater porosity of this membrane as compared with mammalian plasma membranes.

This study was supported in part by the Institute of Comparative Medicine, School of Veterinary Medicine, University of Georgia, Athens, Georgia, under grant D I764-I20 (NIH General Research Veterinary Medicine).

\section{REFERENCES}

BernheImer, A.W. (I953). Synthesis of type III pneumococcal polysaccharide by suspensions of resting cells. Journal of Experimental Medicine 97, 59I-600.

COlvin, J. R. \& BeER, M. (1960). The formation of cellulose microfibrils in suspensions of Acetobacter xylinum. Canadian Journal of Microbiology 6, 63I-637.

Craig, E. L., Frajola, W. J. \& Greider, M. H. (1962). An embedding technique for electron microscopy using Epon 8I 2. Journal of Cell Biology 12, 190-194.

Heidelberger, M., Kendall, F. E. \& SCherp, H. W. (1936). The specific polysaccharides of types I, II, and III pneumococcus. Journal of Experimental Medicine 64, 559-572.

Hershley, A. D. (I940). The role of diffusion in the pneumococcus antipneumococcus reaction. Journal of Immunology 39, 383-396.

JoNes, H. C., Roth, I. L. \& SANDERs, W. M. (1969). Electron microscopic study of a slime layer. Journal of Bacteriology 99, 316-325.

Dabaw, L. L. \& Mosley, V. M. (1954). Demonstration of striated fibers in the capsule of the Lisbonne strain lysogenic Escherichia coli. Journal of Bacteriology 67, 577-584.

Lautrop, H., Reyn, A. \& Birch-Anderson, A. (I964). A comparative electron microscopic study of the cell walls of Gram-negative bacteria. Proceedings of the I4th Scandinavian Congress of Pathology and Microbiology (Universitets ferlaget, Oslo, June 1964) 25-27, 157-160.

LufT, J. H. (196I). Improvements in epoxy resin embedding methods. Journal of Biophysical and Biochemical Cytology 9, 409-414.

LuFT, J. H. (1964). Electron microscopy of cell extraneous coats as revealed by ruthenium red staining. Journal of Cell Biology 23, $54 \mathrm{~A}$.

LUfT, J. H. (I97I). Ruthenium red and ruthenium violet. I. Chemistry purification, methods of use for electron microscopy and mechanism of action. Anatomical Record 171, 347-368.

Millman, B. \& Colvin, J. R. (196I). The formation of cellulose microfibrils by Acetobacter xylinum in agar surfaces. Canadian Journal of Microbiology 7, 383-387.

Millonig, G. \& MarinozZi, V. (1968). Fixation and embedding in electron microscopy. In Advances in Optical and Electron Microscopy, vol. 2, pp. 25I-34I. Edited by R. Barber and V. E. Cosslett. London: Academic Press.

Mudd, S., Heinmets, F. \& Anderson, T. F. (1943). Bacterial morphology as shown by the electron microscope. VI. Capsule, cell wall and inner protoplasm of pneumococcus type III. Journal of Bacteriology 46, 205-2II. 
Ohad, I., Danon, D. \& Hestrin, S. (1962). Synthesis of cellulose by Acetobacter xylinum. V. Ultrastructure of polymer. Journal of Cell Biology 12, 3I-46.

RATE, J. L. \& ORDAL, E. J. (I967). The fine structure of Chondrococcus columnaris. III. The surface layers of Chondrococcus columnaris. Journal of Cell Biology 35, 37-50.

StaUbli, W. (1963). A new embedding technique for electron microscopy combining a water-soluble epoxy resin (Durcupan) with water-insoluble Araldite. Journal of Cell Biology r6, 197-199.

Stoddart, R. W. \& Tipton, K. F. (1968). Studies on the conformation of polygalacturonic acid solution. Biochemical Journal ro9, 21 P-22 P.

Watson, M. L. (1958). Staining of tissue sections for electron microscopy with heavy metals. Journal of Biophysical and Biochemical Cytology 4, 475-478.

Wilkinson, J. F., Duguid, J. P. \& EDMunds, P. N. (1954). The distribution of polysaccharide production in Aerobacter and Escherichia strains and its relation to antigenic character. Journal of General Microbiology II, 59-72. 